Article

\title{
Functionalization of Partially Bio-Based Poly(Ethylene Terephthalate) by Blending with Fully Bio-Based Poly(Amide) 10,10 and a Glycidyl Methacrylate-Based Compatibilizer
}

\author{
Maria Jorda ${ }^{1}$, Sergi Montava-Jorda ${ }^{2}$, Rafael Balart ${ }^{1} \oplus$, Diego Lascano ${ }^{1,3, *} \oplus$, Nestor Montanes ${ }^{1}$ \\ and Luis Quiles-Carrillo ${ }^{1}$ (D) \\ 1 Technological Institute of Materials (ITM), Universitat Politècnica de València (UPV), \\ Plaza Ferrándiz y Carbonell 1, 03801 Alcoy, Spain \\ 2 Department of Mechanical Engineering and Materials (DIMM), Universitat Politècnica de València (UPV), \\ Plaza Ferrándiz y Carbonell 1, 03801 Alcoy, Spain \\ 3 Escuela Politécnica Nacional, Quito 17-01-2759, Ecuador \\ * Correspondence: dielas@epsa.upv.es; Tel.: +34-966-528-433
}

Received: 19 July 2019; Accepted: 9 August 2019; Published: 10 August 2019

\begin{abstract}
This work shows the potential of binary blends composed of partially bio-based poly(ethyelene terephthalate) (bioPET) and fully bio-based poly(amide) 10,10 (bioPA1010). These blends are manufactured by extrusion and subsequent injection moulding and characterized in terms of mechanical, thermal and thermomechanical properties. To overcome or minimize the immiscibility, a glycidyl methacrylate copolymer, namely poly(styrene-ran-glycidyl methacrylate) (PS-GMA; Xibond ${ }^{\text {TM }}$ 920) was used. The addition of $30 \mathrm{wt} \%$ bioPA provides increased renewable content up to $50 \mathrm{wt} \%$, but the most interesting aspect is that bioPA contributes to improved toughness and other ductile properties such as elongation at yield. The morphology study revealed a typical immiscible droplet-like structure and the effectiveness of the PS-GMA copolymer was assessed by field emission scanning electron microcopy (FESEM) with a clear decrease in the droplet size due to compatibilization. It is possible to conclude that bioPA1010 can positively contribute to reduce the intrinsic stiffness of bioPET and, in addition, it increases the renewable content of the developed materials.
\end{abstract}

Keywords: bio-based; poly(ethyelene terephthalate)—PET; poly(amide) 1010—PA1010; mechanical properties; morphology; compatibilization; Xibond ${ }^{\mathrm{TM}} 920$

\section{Introduction}

In the last decade, there has been a noticeable increase in the sensitiveness and concern about environment. Topics such as sustainable development, circular economy, carbon footprint, petroleum depletion, among others are gaining relevance [1-3]. Therefore, many research works are focused on the development of environmentally friendly materials to positively contribute to a sustainable development. This situation is particularly aggravated in the polymer industry which accounts for the use of large amounts of petroleum-derived plastics with the subsequent environmental impact both at the origin (petroleum) and at the end of the life cycle or disposal (most of the petroleum-based polymers are not biodegradable). For these reasons, the polymer industry is demanding continuously environmentally friendly polymers It is worthy to note the important role that some petroleum-based polymers have acquired in the last decade. In particular, aliphatic polyesters such as poly( $\varepsilon$-caprolactone) (PCL) [4] poly(butylene succinate) (PBS) [5], poly(glycolic 
acid) (PGA) [6], poly(butylene succinate-co-adipate) (PBSA) and their blends/composites with other polymers and lignocellulosic fillers have gained interest in several industrial sectors, despite being petroleum-based, as they can undergo degradation under controlled compost soil [7-9]. Another promising group of environmentally friendly polymers includes polysaccharides (and derivatives), protein-based polymers and bacterial polymers. Poly(lactic acid) (PLA), together with thermoplastic starch (TPS), are perhaps the most studied polymers in this group that can be derived from polysaccharides [10], in particular, from starch-rich materials, i.e., potato, corn, bagasse, and so on. PLA is commercially available at a competitive price. Protein-based polymers include some interesting materials as gluten, soy protein, collagen, rape-seed protein, among others, that find applications in the form of film, parts, fibers, and so on [11-14]. Finally, bacterial polymers include all poly(hydroxyalkanoates) (PHAs) which are expected to invade the market soon $[15,16]$. Some of the most interesting PHAs include poly(3-hydroxybutyrate) (PHB), poly(3-hydroxybutyrate-co-valerate) (PHBV), poly(3-hydroxybutyrate-co-hexanoate) (PHBH) [17,18].

Despite all of these materials representing a clear environmental efficiency, in general, their properties are far from those of petroleum-derived commodity and engineering plastics. For this reason, many studies have been focused on obtaining commodity and engineering plastics from renewable resources. These show identical properties to their petroleum-based counterparts, but they offer interesting environmental efficiency as they can be totally or partially derived from renewable materials, usually bio-products coming from the food industry and agroforestry. Bio-based poly(ethylene) (bioPE), is a commodity that is synthesised from bioethanol from sugarcane and can reach almost $95 \%$ bio-based content. This shows a clear positive environmental efficiency compared to poly(ethylene) from crude oil [19-21]. Currently, bioPE is available worldwide at a relatively cost competitive price and it has been recently used as a base material for 3D printing [22]. In regard to engineering plastics, it is worthy to note the increasing consumption of bio-based poly(ethylene terephthalate) (bioPET) and bio-based poly(amides) (PAs) [23-26]. In recent years, poly(ethylene furanoate) (PEF) has generated great expectations as it can be fully bioderived and could potentially substitute poly(ethylene terephthalate) (PET) polymers [27]. Although in the future bioPET can reach $100 \%$ renewable source since there is a bio-route to synthesise terephthalic acid (TA) [28,29], currently its bio-based content is related to the ethylene glycol which can give approximately $30 \%$ bio-based content. Regarding bioPAs, castor oil plays a key role as a starting material for PA synthesis [30]. It is worthy to note bioPAs are engineering plastics with different bio-sourced content. Thus, bioPA610 typically offers 60-63\% renewable content [31]; bioPA1012 usually offers a renewable content of $45 \%$ and bioPA1010 can be $100 \%$ derived from renewable resources from sebacic acid and 1,10-decamethylene diamine (DMDA), both derived from ricinoleic acid [32]. Some of these bioPAs have alternative eco-routes and could be fully bioderived. PET and, recently bioPET are widely used in the packaging industry for bottles. Despite this, some beverages (especially oxygen-sensitive beverages) require the use of scavengers that usually are derived from poly(amides), so that poly(amides) are increasingly present in the PET bottle-to-bottle cycle [33].

This work explores the potential of high bio-based content blends of partially bio-based poly(ethylene terephthalate) (bioPET) and fully bio-based poly(amide) 10,10 (bioPA1010) up to $30 \mathrm{wt} \%$. Although bioPET and bioPA1010 show similar properties to their corresponding petroleum-derived counterparts, currently bioPET only contains approximately $30 \mathrm{wt} \%$ of biobased content while bioPA10120 can be fully bioderived from castor oil. The production of these partially or totally biobased polymers is increasing in a remarkable way and new biobased routes are being developed for partially biobased polymers to achieve $100 \%$ biosourced materials. This can have a positive effect on sustainable development and circular economies as most of the biobased building blocks could be obtained from by-products of the food or agroforestry industries. For these reasons, blending these two polymers is attractive from an environmental standpoint as these blends could reach high biobased contents without compromising other properties, thus leading to engineering blends with potential in the packaging industry. Due to their immiscibility, a glycidyl compatibilizer, namely a 
poly(styrene-ran-glycidyl methacrylate) copolymer (PS-GMA) Xibond ${ }^{\mathrm{TM}} 920$ was used. The effect of both bioPA1010 and the PS-GMA compatibilizer are evaluated on their mechanical, thermal and thermomechanical properties. The novelty of this work is the high renewable content that can be obtained by these blends together with improved toughness.

\section{Experimental}

\subsection{Materials}

The partially bio-based poly(ethylene terephthalate), bioPET and fully bio-based poly(amide) 1010 were supplied by NaturePlast (Ifs, France). Table 1 summarizes the main properties of these commercial grades.

Table 1. Commercial grades and main properties of partially bio-based poly(ethylene terephthalate)—bioPET and fully bio-based poly(amide) 1010, supplied by NaturePlast.

\begin{tabular}{ccc}
\hline Property & bioPET & bioPA1010 \\
\hline Grade & BioPET 001 & NP BioPA1010-201 \\
wt \% bio-based & 30 & 100 \\
Melt temperature $\left({ }^{\circ} \mathrm{C}\right)$ & $240-260$ & $190-210$ \\
Density $\left(\mathrm{g} \mathrm{cm}^{-3}\right)$ & $1.3-1.4$ & 1.05 \\
Intrinsic viscosity $\left(\mathrm{mL}^{\circ} \mathrm{g}^{-1}\right)$ & $75-79$ & $84-900^{*}$ \\
\hline
\end{tabular}

The selected compatibilizer was a poly(styrene-glycidyl methacrylate) random copolymer (PS-GMA) Xibond ${ }^{\text {TM }} 920$ and was kindly provided by Polyscope (Geleen, The Netherlands). The GMA functionality has excellent affinity with polycondensates which can result in compatibilization, chain extension and/or branching. Figure 1 shows a scheme of the different materials used in this research.

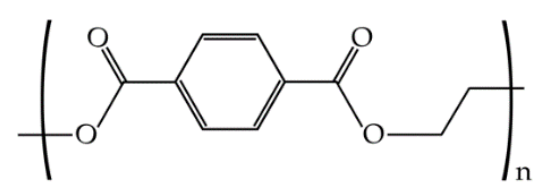

poly(ethylene terephthalate) - PET<smiles>CN(CCCCCCCCCCNC(=O)CCCCCCCCC(=O)C(C)(C)C)C(C)(C)C</smiles>

poly(amide) 10,10 - PA1010<smiles>CC(C)(C)CC(C1CCCCC1)C(C)(C)CC(C)(C)C(=O)OCC1CO1</smiles>

poly(styrene-ran-glycidyl methacrylate) - PS-GMA [Xibond ${ }^{\mathrm{TM}}$ 920]

Figure 1. Schematic representation of the chemical structure of bio(polyethylene terephthalate), bio-based poly(amide) 10,10 and glycidyl copolymer compatibilizer Xibond ${ }^{\text {TM }} 920$. 


\subsection{Manufacturing of Binary BioPET/BioPA Blends}

Initially, all materials (see Table 2 for code and composition) were dried at $60^{\circ} \mathrm{C}$ for $24 \mathrm{~h}$ to remove residual moisture. After this, the corresponding amounts of each material were mechanically mixed in a zipper bag, and then were fed into the hopper of a twin-screw co-rotating extruder from DUPRA S.L. (Castalla, Spain). The screw diameter was $30 \mathrm{~mm}$ and the temperature profile was set to four different barrels as follows (from the hopper to the die): $250{ }^{\circ} \mathrm{C}, 260^{\circ} \mathrm{C}, 260^{\circ} \mathrm{C}$ and $260{ }^{\circ} \mathrm{C}$. The rotating speed was set to $20 \mathrm{rpm}$. After this initial compounding stage, the obtained blends were cooled down to room temperature and subsequently pelletized for further processing by injection moulding. The injection moulding machine used was a Mateu \& Solé mod. Meteor 270/75 (Barcelona, Spain). The temperature profile was $240{ }^{\circ} \mathrm{C}$ (feeding Hopper), $245^{\circ} \mathrm{C}, 250^{\circ} \mathrm{C}$ and $255^{\circ} \mathrm{C}$ (injection nozzle). The filling time was set at $1 \mathrm{~s}$ and the cooling time was $5 \mathrm{~s}$.

Table 2. The compositions and labeling of binary bioPET/bioPA1010 blends. The bio-based content is calculated considering that bioPET contains an average bio-based content of $30 \mathrm{wt} \%$, bioPA1010 is $100 \%$ bio-based and Xibond ${ }^{\mathrm{TM}} 920$ is petroleum-derived ( $0 \mathrm{wt} \%$ bio-based).

\begin{tabular}{|c|c|c|c|c|}
\hline Label & bioPET (wt \%) & bioPA (wt \%) & Xibond ${ }^{\mathrm{TM}}(\mathrm{phr})^{*}$ & Bio-based content (wt \%) \\
\hline PET100 & 100 & - & - & 30.0 \\
\hline PET90 & 90 & 10 & - & 37.0 \\
\hline PET80 & 80 & 20 & - & 44.0 \\
\hline PET70 & 70 & 30 & - & 51.0 \\
\hline PET70Xibond1 & 70 & 30 & 1 & 50.5 \\
\hline PET70Xibond3 & 70 & 30 & 3 & 49.5 \\
\hline PET70Xibond5 & 70 & 30 & 5 & 48.6 \\
\hline
\end{tabular}

* phr: weight grams of Xibond ${ }^{\text {TM }} 920$ per one hundred grams bioPET/bioPA blend.

\subsection{Mechanical Characterization}

The tensile properties were obtained through ISO 527-2:2012 standard on injection moulded dog-bone samples using an electromechanical machine ELIB-50 from S.A.E Ibertest (Madrid, Spain). All tests were run at a cross-head speed of $10 \mathrm{~mm} \cdot \mathrm{min}^{-1}$, using a $5 \mathrm{kN}$ loadcell. Regarding the impact strength, it was estimated through a Charpy test using a 6-J pendulum from Metrotec S.A. (San Sebastián, Spain) on the unnotched rectangular samples, following indications of ISO 179-1:2010. Finally, the hardness was obtained by using the Shore method in a 673-D durometer from J. Bot Instruments (Barcelona, Spain) as suggested by ISO 868:2003. All mechanical tests were run at room temperature and at least five different samples were tested to obtain the average characteristic parameters.

\subsection{Thermal Characterization}

Differential scanning calorimetry (DSC) was used to study the main thermal transitions of the manufactured materials. DSC tests were carried out on a Q200 calorimeter from TA Instruments (New Castle, DE, USA). A dynamic thermal program was scheduled in three different stages using standard aluminium crucibles. The first heating from $30^{\circ} \mathrm{C}$ up to $280^{\circ} \mathrm{C}$ was followed by a cooling down to $0{ }^{\circ} \mathrm{C}$ and a second heating up to $350^{\circ} \mathrm{C}$. The heating/cooling rate was set to $10^{\circ} \mathrm{C} \cdot \mathrm{min}^{-1}$ with a constant nitrogen flow rate of $50 \mathrm{~mL} \mathrm{~min}^{-1}$. The maximum degree of crystallinity was calculated for both bioPET and bioPA (see Equation 1) by comparing the melt enthalpy $\left(\Delta H_{m}\right)$ with the corresponding melt enthalpy of a theoretical $100 \%$ crystalline polymer $\left(H_{m}{ }^{0}\right.$ for PET $=140.1 \mathrm{~J} \cdot \mathrm{g}^{-1}$ [34], and $244.0 \mathrm{~J} \cdot \mathrm{g}^{-1}$ for PA1010 [35]), and considering the weight fraction of each polymer in the blend (w).

$$
\% \chi_{c}=\frac{\Delta H_{m}}{\Delta H_{m}^{0} \cdot w}
$$


Additional thermal characterization was carried out by thermogravimetry (TGA) in a TGA/SDTA 851 thermobalance from Mettler-Toledo (Schwerzenbach, Switzerland). A dynamic heating program from $20^{\circ} \mathrm{C}$ to $700{ }^{\circ} \mathrm{C}$ at a heating rate of $20^{\circ} \mathrm{C} \cdot \mathrm{min}^{-1}$ was applied to an average sample weight of $8 \mathrm{mg}$ in an air atmosphere in alumina crucibles.

\subsection{Morphology Characterization}

Field emission scanning electron microscopy (FESEM) was used to reveal the morphology of the fractured surfaces blends after the impact tests. A FESEM microscope from Oxford Instruments (Abingdon, UK) was used working at an acceleration voltage of $1.5 \mathrm{kV}$. As the polymer blends were not electrically conducting materials, a metal sputtering process was carried out to provide conducting properties to the samples and to avoid sample charge. All fractured samples were coated with an ultrathin gold-palladium alloy in a Quorum Technologies Ltd. EMITECH model SC7620 sputter coater (East Sussex, UK).

\subsection{Thermo-Mechanical Characterization}

The effect of the temperature on the mechanical properties and dimensional stability was studied by dynamic-mechanical thermal analysis (DMTA) and thermomechanical analysis (TMA) respectively. Thermomechanical analysis was carried out in a Q400 thermoanalizer from TA Instruments (New Castle, $\mathrm{DE}, \mathrm{USA})$. The particular conditions for this test were a dynamic thermal sweep from $0{ }^{\circ} \mathrm{C}$ up to $140{ }^{\circ} \mathrm{C}$ at a constant heating rate of $2{ }^{\circ} \mathrm{C} \cdot \mathrm{min}^{-1}$ with an applied load of $20 \mathrm{mN}$. Regarding dynamic-mechanical thermal characterization, an oscillatory rheometer AR-G2 from TA Instruments (Delaware, USA), equipped with a special clamp system for solid samples (working in a combination of shear-torsion stresses) was used. The maximum shear deformation (\%) was set to $0.1 \%$ at a frequency of $1 \mathrm{~Hz}$. The thermal sweep was scheduled from $20^{\circ} \mathrm{C}$ up to $160^{\circ} \mathrm{C}$ at a heating rate of $5{ }^{\circ} \mathrm{C} \cdot \mathrm{min}^{-1}$.

\section{Results and Discussion}

\subsection{Mechanical Properties and Morphology of Binary BioPET/BioPA Blends}

It has been reported that mechanical properties of PET are highly dependent on the processing conditions $[36,37]$. In addition, the mechanical properties of PET polymers are also dependent on the thermal treatment, quenching, annealing, etc. As it can be seen in Figure 2, the mechanical and thermal properties of bioPET are highly dependent on the annealing time. To assess this, bioPET has been subjected to different annealing times and studied by dynamic-mechanical thermal analysis (DMTA). Figure 2a shows the evolution of the storage modulus $\left(G^{\prime}\right)$ as a function of the increasing temperature. DMTA is based on the use of a dynamical time-dependent stress function, $\sigma=\sigma_{0} \sin (\omega t)\left[\sigma_{0}\right.$ is the maximum stress and $\omega$ represents the frequency] which produces a sinusoidal strain $(\varepsilon)$ given by $\varepsilon$ $=\varepsilon_{0} \sin (\omega \mathrm{t}-\delta)$ where $\varepsilon_{0}$ is the maximum strain and $\delta$ is the phase angle which represents the delay (viscous) properties of the material. As the modulus represents the ratio between the maximum stress to the maximum strain, then it is possible to define the complex modulus $\left(G^{*}\right)$ as $\sigma_{0}=\varepsilon_{0} G^{*} \sin (\omega t+\delta)$. This expression can be expanded to give $\sigma_{0}=\varepsilon_{0} G^{*} \sin (\omega t) \cos (\delta)+\varepsilon_{0} G^{*} \cos (\omega t) \sin (\delta)$, which can be expressed as $\sigma_{0}=\varepsilon_{0} G^{\prime} \sin (\omega t)+\varepsilon_{0} G^{\prime \prime} \cos (\omega t)$ with $G^{\prime}=G^{*} \cos (\delta)$ and $G^{\prime \prime}=G^{*} \sin (\delta)$, thus leading to an elastic response related to $G^{\prime}$ (storage modulus) and a viscous response related to $G^{\prime \prime}$ (loss modulus). As it can be derived, the ratio between the loss modulus $\left(G^{\prime \prime}\right)$ to the storage modulus $\left(G^{\prime}\right)$ represents the damping factor or $\tan \delta$, which is directly related to the lost energy due to viscoelastic behaviour.

It can be seen that, neat bioPET shows a characteristic DMTA curve characterized by different zones. Below $60^{\circ} \mathrm{C}$, the storage modulus remains almost constant at a temperature range comprising between $60^{\circ} \mathrm{C}$ and $80^{\circ} \mathrm{C}$, and a remarkable decrease in $G^{\prime}$ occurs. This decrease of near three orders of magnitude is representative of the glass transition process. In addition, information is provided about the high amorphous structure due to this three-fold change. Then, at the temperature range comprising between $106^{\circ} \mathrm{C}$ and $125^{\circ} \mathrm{C}$, it is possible to observe an increase in $G^{\prime}$ which is directly 
related to the cold crystallization process which involves packing of polymer chains in an ordered way which gives increased stiffness. After 15 min annealing time at $110^{\circ} \mathrm{C}$, the morphology of the DMTA curve has changed in a remarkable way. As it can be seen, the decrease in $G^{\prime}$ is remarkably lower. The glass transition process has shifted to higher temperatures (probably due to the restriction of chain mobility in the crystalized structure) but it is still possible to find a slight increase in $G^{\prime}$ in the temperature range comprising between $106-120^{\circ} \mathrm{C}$. Nevertheless, with an annealing of $30 \mathrm{~min}$, it is possible to conclude that the maximum crystallinity is achieved. The curves for 30 and $45 \mathrm{~min}$ are shifted to the right (higher temperatures) and the cold crystallization process has completely disappeared. Similar findings have been reported by A. Bartolotta et al. [38] who showed a remarkable change in the glass transition onset from $40{ }^{\circ} \mathrm{C}$ (cold-drawn PET) up to $90^{\circ} \mathrm{C}$ in highly crystalline PET. A. Bartolotta et al. attribute this phenomenon to an increase in density on glassy domains related to the presence of more crystal-packed domains and conclude that there is a link between the chain stiffness since there is a connection between the bulk glass to the ordered structures. Z. Chen et al. [39] have also reported different crystallization mechanisms depending on the annealing temperature with remarkable changes, not only in the glass transition process but also on the melt temperature. In addition, the $G^{\prime}$ values are higher with increasing annealing time.

Figure $2 \mathrm{~b}$ shows the evolution of the dynamic damping factor, $\tan \delta$. Notably, the maximum damping factor value decreases with the increasing annealing time. This is consistent with the damping factor definition which shows the ratio between the loss modulus $\left(G^{\prime \prime}\right)$ and the storage modulus $\left(G^{\prime}\right)$. As the material becomes stiffer by the cold crystallization process, the denominator is higher, and this leads to lower damping factor values. It is worthy to note that the damping factor is related to the lost energy to stored energy ratio. As the annealing time increases, the material becomes stiffer and this is responsible for less lost energy. There are several methods to assess the glass transition temperature $\left(T_{\mathrm{g}}\right)$ by using several methods from DMTA, i.e., the onset of the $G^{\prime}$ decrease, the peak maximum of $G^{\prime \prime}$ or the peak maximum of the damping factor. The peak temperature of $\tan \delta$ is widely used to give accurate values of $T_{\mathrm{g}}$. The un-annealed bioPET shows a $T_{\mathrm{g}}$ of $79.9^{\circ} \mathrm{C}$ which increases progressively with increasing annealing time at $110^{\circ} \mathrm{C}$ resulting in values of $84.8^{\circ} \mathrm{C}(15 \mathrm{~min}$ annealing $), 93.7^{\circ} \mathrm{C}$ (30 min annealing) and $96.3-96.4^{\circ} \mathrm{C}$ for 45 and 60 min annealing. These results are in total accordance with those reported by A. Bartolotta et al. [38], who showed a change in the onset of $T_{\mathrm{g}}$ (using the $G^{\prime}$ method) from $40{ }^{\circ} \mathrm{C}$ up to $90^{\circ} \mathrm{C}$.

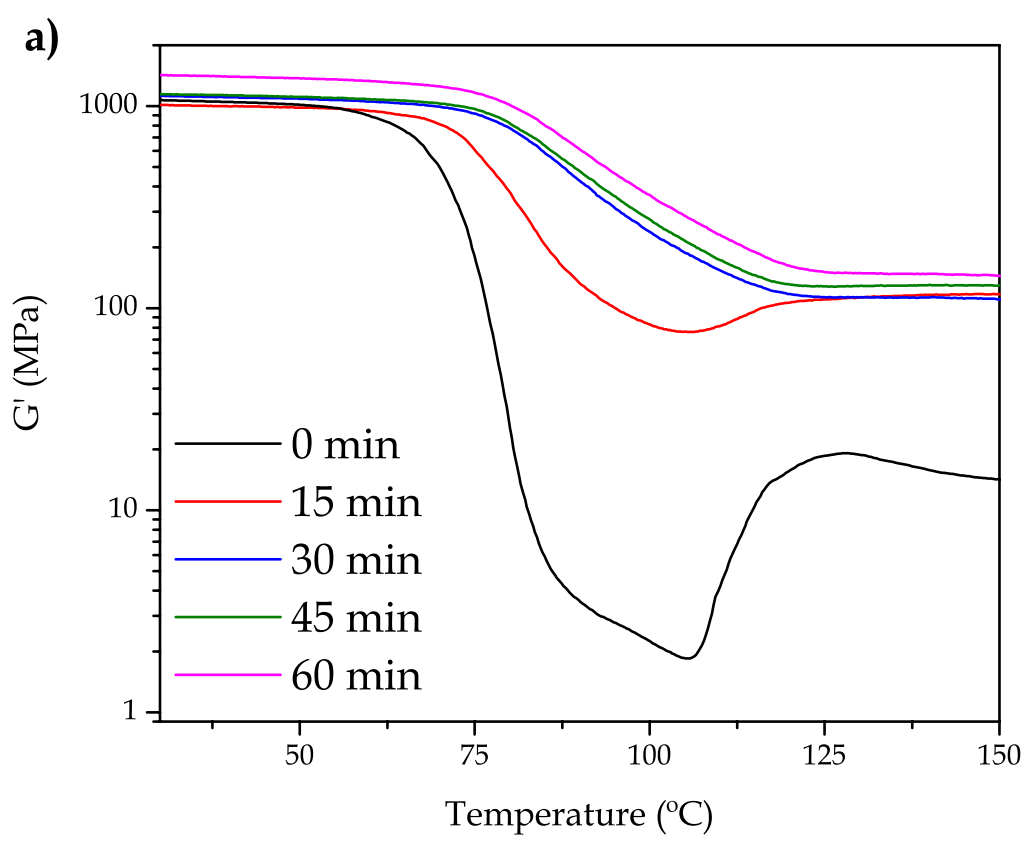

Figure 2. Cont. 


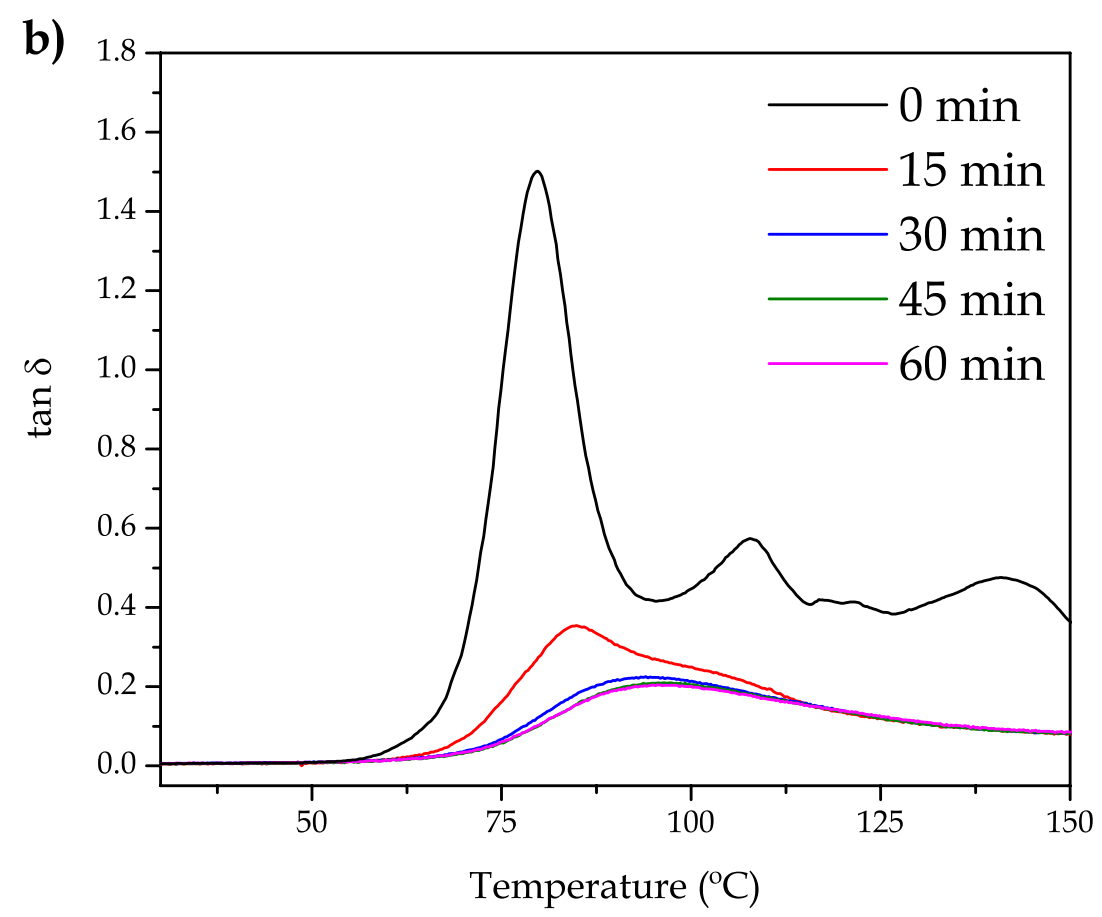

Figure 2. The effect of annealing on the dynamic-mechanical properties of neat bioPET subjected to different annealing times, (a) storage modulus, $G^{\prime}$ and (b) dynamic damping factor $(\tan \delta)$.

In this work, bioPET and its blends have been characterized without any annealing process, just as obtained by the injection moulding. Neat bioPET showed a tensile strength $\left(\sigma_{t}\right)$ of $46.7 \mathrm{MPa}$ and a relatively low elongation at yield $\left(\varepsilon_{y}\right)$ of $3.87 \%$ which leads to a stiff material. The effect of the addition of bioPA to bioPET produces two important effects. On the one hand, the tensile strength decreases as expected in an immiscible blend as reported by K.C. Chiou et al. [40], in PA6/PBT binary blends, but the decrease is not so pronounced. In fact, the maximum percentage decrease is close to $11 \%$ for the uncompatibilized blend containing $30 \mathrm{wt} \%$ bioPA. It is important to remark that the bio-based content of the blend containing $30 \mathrm{wt} \%$ bioPA is above $50 \%$ which is a positive property from an environmental point of view. On the other hand, the addition of a flexible polymer such as bioPA, provides improved elongation at yield up to values of $4.8 \%$ which represents a percentage increase of $24 \%$, thus leading to improved ductile behaviour. The effect of the poly(styrene-ran-glycidyl methacrylate) copolymer (PS-GMA) Xibond ${ }^{\mathrm{TM}} 920$ gives interesting results. It is worthy to note that the addition of 3 phr Xibond ${ }^{\mathrm{TM}} 920$ leads to higher tensile strength regarding neat bioPET, reaching values of $47.1 \mathrm{MPa}$ with a parallel increase in elongation up to values of $6.09 \%$ (57\% increase compared to neat bioPET and $27 \%$ the same composition without compatibilizer). This indicates that $\mathrm{Xibond} \mathrm{d}^{\mathrm{TM}}$ 920 is providing somewhat compatibilization properties to this binary system. Similar findings have been obtained using a $\mathrm{Zn}^{2+}$ ionomer on PET/PA6 blends with improved elongation at break and toughness compared to an uncompatibilized blend [41]. Y. Huang et al. [42], reported the exceptional compatibilizing effect of the glycidyl group by using an epoxy resin (E-44) as a compatibilizer in PET/PA6 blends. C.T. Ferreira et al. [43] reported the potential of reactive extrusion of recycled PET and recycled PA by a reaction of the carboxyl end-chain groups in PET and the amine end-chain groups in PA with a noticeable improvement in mechanical properties using tin(II) 2-ethylhexanoate as a trans-reaction catalyst. Regarding the hardness, as both polymers show similar Shore D values, it is not possible to observe a tendency with varying composition as shown in Table 3. 
Table 3. The mechanical properties of binary bioPET/bioPA blends obtained from tensile, hardness and Charpy tests.

\begin{tabular}{|c|c|c|c|c|}
\hline Code & $\sigma_{b}(\mathrm{MPa})$ & $\varepsilon_{y}(\%)$ & Shore D & Impact Strength $\left(\mathrm{kJ} \cdot \mathrm{m}^{-2}\right)$ \\
\hline PET100 & $46.7 \pm 2.3$ & $3.87 \pm 0.30$ & $75 \pm 2.5$ & $23.1 \pm 4.4$ \\
\hline PET90 & $41.5 \pm 4.6$ & $4.30 \pm 0.39$ & $75 \pm 2.5$ & $27.0 \pm 3.8$ \\
\hline PET80 & $42.8 \pm 2.5$ & $4.71 \pm 1.04$ & $75 \pm 2.8$ & $30.3 \pm 3.6$ \\
\hline PET70 & $41.4 \pm 0.6$ & $4.80 \pm 0.40$ & $75 \pm 2.9$ & $40.5 \pm 9.9$ \\
\hline PET70Xibond1 & $41.3 \pm 0.8$ & $5.01 \pm 0.69$ & $73 \pm 2.9$ & $42.9 \pm 2.7$ \\
\hline PET70Xibond3 & $47.1 \pm 1.1$ & $6.09 \pm 0.86$ & $75 \pm 2.3$ & $43.4 \pm 1.6$ \\
\hline PET70Xibond5 & $40.6 \pm 4.5$ & $6.63 \pm 1.94$ & $74 \pm 2.5$ & $44.6 \pm 3.9$ \\
\hline
\end{tabular}

Regarding the impact strength which is measured through the Charpy impact test, it is worthy to note that all the developed materials have increased impact strength in comparison to neat bioPET. Neat bioPET offers a quite brittle behaviour with an impact-absorbed energy of $23.1 \mathrm{~kJ} \cdot \mathrm{m}^{-2}$. The uncompatibilized binary blend with $10 \mathrm{wt} \%$ bioPA1010 offers an increased impact strength of $27.0 \mathrm{~kJ} \cdot \mathrm{m}^{-2}$ (which represents a percentage increase of approximately $16.9 \%$ ). This result is in total agreement with other ductile properties such as elongation at yield $\left(\varepsilon_{\mathrm{y}}\right)$. Y. Yan et al. [44] reported the lubricant effect of PA56 on PET blends at a molecular level with the subsequent effect on mechanical properties. This phenomenon has been observed in other binary blends composed of a brittle polymer matrix in which a rubber-like material is finely dispersed, even with poor miscibility between them. J. Urquijo et al. [45] reported a remarkable increase in both elongation at the break and impact strength in binary blends of poly(lactic acid) (PLA) and different loadings of poly( $\varepsilon$-caprolactone) (PCL). J. Urquijo et al. demonstrated the relevance of the elongation rate on the final elongation and, regarding the impact strength, they attributed the improvement to the small particle size of PCL-rich domains embedded in the brittle PLA-rich matrix which positively contributed to absorb energy in impact conditions. Similar findings have been reported with PLA/PCL, PHB/PCL, PLA/PBS binary blends [46-49], ternary PLA/PHB/PCL blends [50], and some poly(ester) copolymers [51]. This improved toughness is more evident in an uncompatibilzed blend containing $30 \mathrm{wt} \%$ bioPA1010 reaching an impact strength of $40.5 \mathrm{~kJ} \cdot \mathrm{m}^{-2}(75.3 \%$ increase). The effect of the compatibilizer has a positive effect on improved toughness as it can be seen in Table 2. Xibond ${ }^{\mathrm{TM}} 920$ is a random copolymer of poly(styrene-glycidyl methacrylate) (PS-GMA) and gives excellent results in compatibilizing condensation polymers. This is because of the glycidyl methacrylate group which can interact with both hydroxyl end-groups in bioPET and amine (primary or secondary) in bioPA1010, thus leading to somewhat compatibilization with a marked effect on impact strength. The addition of $5 \mathrm{phr}$ Xibond ${ }^{\text {TM }} 920$ gives an impact strength of $44.6 \mathrm{~kJ} \cdot \mathrm{m}^{-2}(93.1 \%$ increase compared to neat bioPET and an additional $10.1 \%$ compared to the uncompatibilized blend containing $30 \mathrm{wt} \%$ bioPA1010). It is evident the positive effect of the compatibilizer in improved toughness. With regard to the bio-based content, the blends with $30 \mathrm{wt} \%$ bioPA with compatibilizer show a bio-based content of approximately $50 \%$. The GMA-based copolymers have been reported as good compatibilizers in different blends containing PAs or polyesters due to their reactivity with both polymers, such as PA6/PP [52,53], PA6/PVF [54], PET/PP [55], HDPE/PET [56].

The improved toughness is directly related to the morphology of the obtained materials. Figure 3 gathers FESEM images of uncompatibilized bioPET/bioPA blends. Figure 3 a shows the fracture surface of neat PET with a typical rigid and brittle material, that is, very smooth surfaces resulting from microcrack appearances and their growth without plastic deformation. This brittle behaviour for neat PET has been reported by A.R. McLauchlin et al. [57] in PET/PLA blends. Figure 3b shows the morphology of the uncompatibilized binary blend containing $10 \mathrm{wt} \%$ bioPA. This morphology is remarkably different to neat bioPET. In particular, it is possible to observe a brittle fracture surface with a noticeable increase in roughness due to presence of small-sized bioPA immiscible droplets embedded into the bioPET matrix. As the bioPA wt $\%$ increases, the roughness is more evident, and the 
characteristic brittle fracture disappears. In Figure 3d, corresponding to the binary blend with $30 \mathrm{wt} \%$ bioPA, it is possible to observe the characteristic droplet-like structure of an immiscible polymer blend in which bioPA appears in the form of spherical droplets with an average size of approximately $3.9 \pm 1.1 \mu \mathrm{m}$. This size is higher than the average size observed for lower bioPA content. It is evident that by increasing the bioPA content, the average particle size increases due to the particle coalescence as reported by A.M. Torres-Huerta et al. [58] on PET/PLA and PET/chitosan blends. Y. Yan et al. [44] reported the high immiscibility of PET blends with PA56 (up to $30 \mathrm{wt} \%$ ) and used dissipative particle dynamics (DPD) to assess the immiscibility of both polymers and how the PA56 domains increase with increasing PA56 content. The poor compatibility between these polymers can be observed at a $30 \mathrm{wt} \%$ bioPA in the blends as the morphology shows the typical spherical bioPA droplets embedded in the matrix (sea-island morphology) as well as some voids with the same average diameter consisting of some bioPA droplets on the holes which have been produced after being pulled out during the impact test. This pulling out occurs because of the poor polymer-polymer interactions.
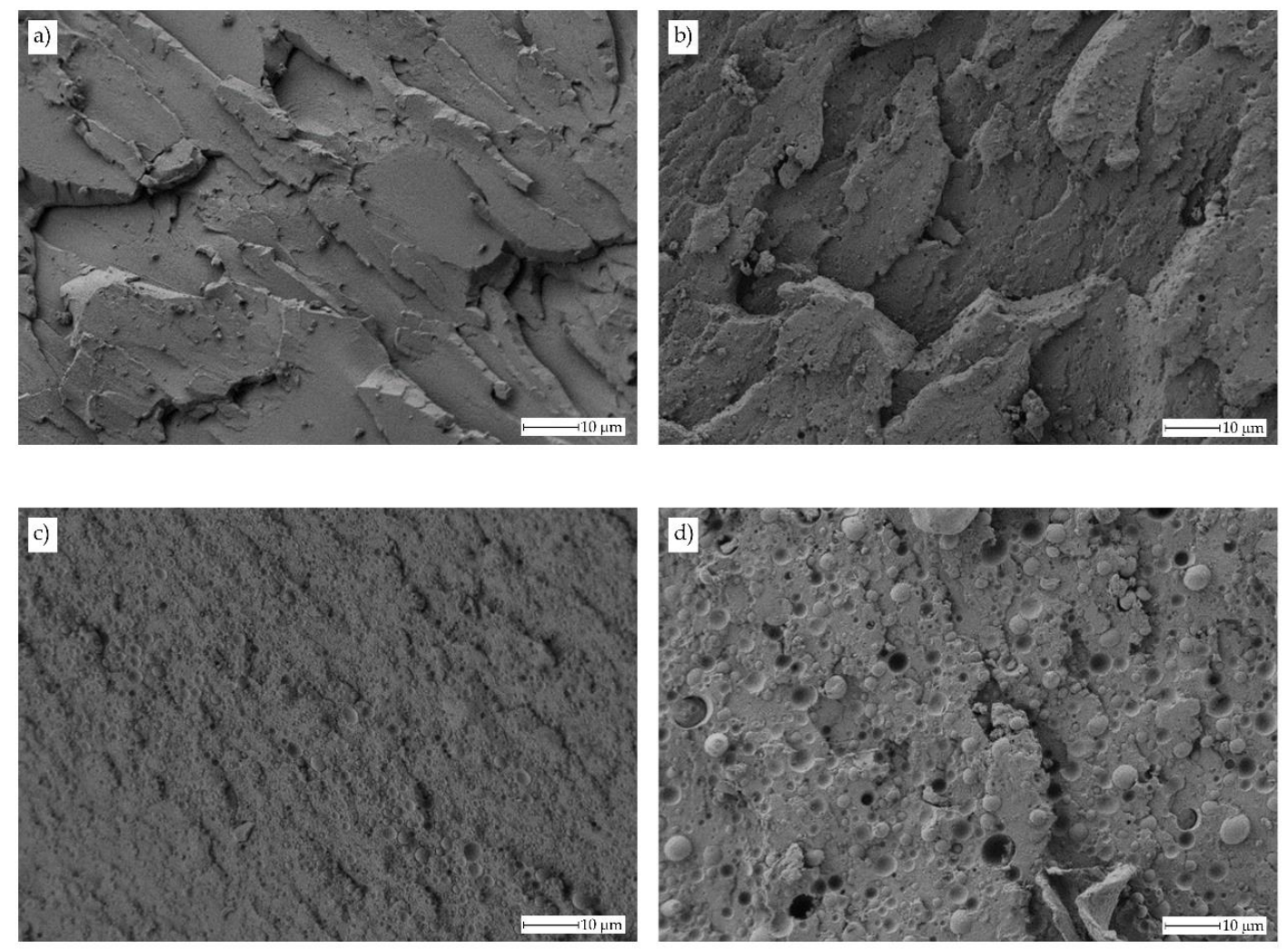

Figure 3. Field emission scanning electron microscope (FESEM) images of the fractured surface from an impact test at $1000 \mathrm{x}$ corresponding to uncompatibilized bioPET/bioPA blends with different bioPA content, (a) $0 \mathrm{wt} \%$ (PET100), (b) $10 \mathrm{wt} \%$ (PET90), (c) $20 \mathrm{wt} \%$ (PET80) and (d) $30 \mathrm{wt} \%$ (PET70).

These results suggest that the poly(styrene-ran-glycidyl methacrylate) copolymer (PS-GMA) can positively contribute to a partial compatibilization effect due to the reaction of the glycidyl groups with both hydroxyl terminal groups in bioPET and amine groups in bioPA [54,55]. Y. Huang et al. [42] reported the reactivity of the glycidyl group of an epoxy resin (E-44) in a PET/PA6 binary blend. As the nature of both bioPET and bioPA is the same as petroleum-derived PET and other semicrystalline polyamides, it is possible to assume similar reactions as described in by Y. Huang et al. That study reported the greater tendency of the glycidyl group to react with polyamide due to the presence of many hydrogen bonding (together with carboxylic and amine end-chains) while the reaction of the glycidyl group with PET is restricted to hydroxyl and carboxyl end-chains. Moreover, Y. Huang et al. further reported evidences of these reactions by extracting the polyamide fraction by formic acid which 
was subjected to FTIR analysis. This analysis showed a shift of the $\mathrm{N}-\mathrm{H}$ bending from 1560 to 1544 $\mathrm{cm}^{-1}$ and shift of the $\mathrm{C}=\mathrm{O}$ stretching from 1662 to $1642 \mathrm{~cm}^{-1}$, both changes indicating the reaction of PA6 with the glycidyl group in E-44 epoxy resin. In addition, the characteristic peaks of PET at 1730, 1104 and $730 \mathrm{~cm}^{-1}$ were also detectable by FTIR thus giving consistency to the grafting process.

The indirect effects of these reactions can also be detectable by a remarkable change in surface morphology as it can be seen in Figure 4. The addition of PS-GMA Xibond ${ }^{\text {TM }} 920$ gives a noticeable decrease in the droplet size of bioPA-rich domains. There is not a great difference between the images corresponding to the compatibilized bioPET/bioPA blends containing 1, 3 or 5 phr PS-GMA. At this magnification $(1000 \times)$, it can be realized that the droplet diameter has been reduced down to values under $1 \mu \mathrm{m}$. This situation can be clearly observed in Figure 5 which shows a comparative FESEM image of the uncompatibilized blend with $30 \mathrm{wt} \%$ bioPA and the same blend with 3 phr PS-GMA Xibond ${ }^{\mathrm{TM}} 920$.
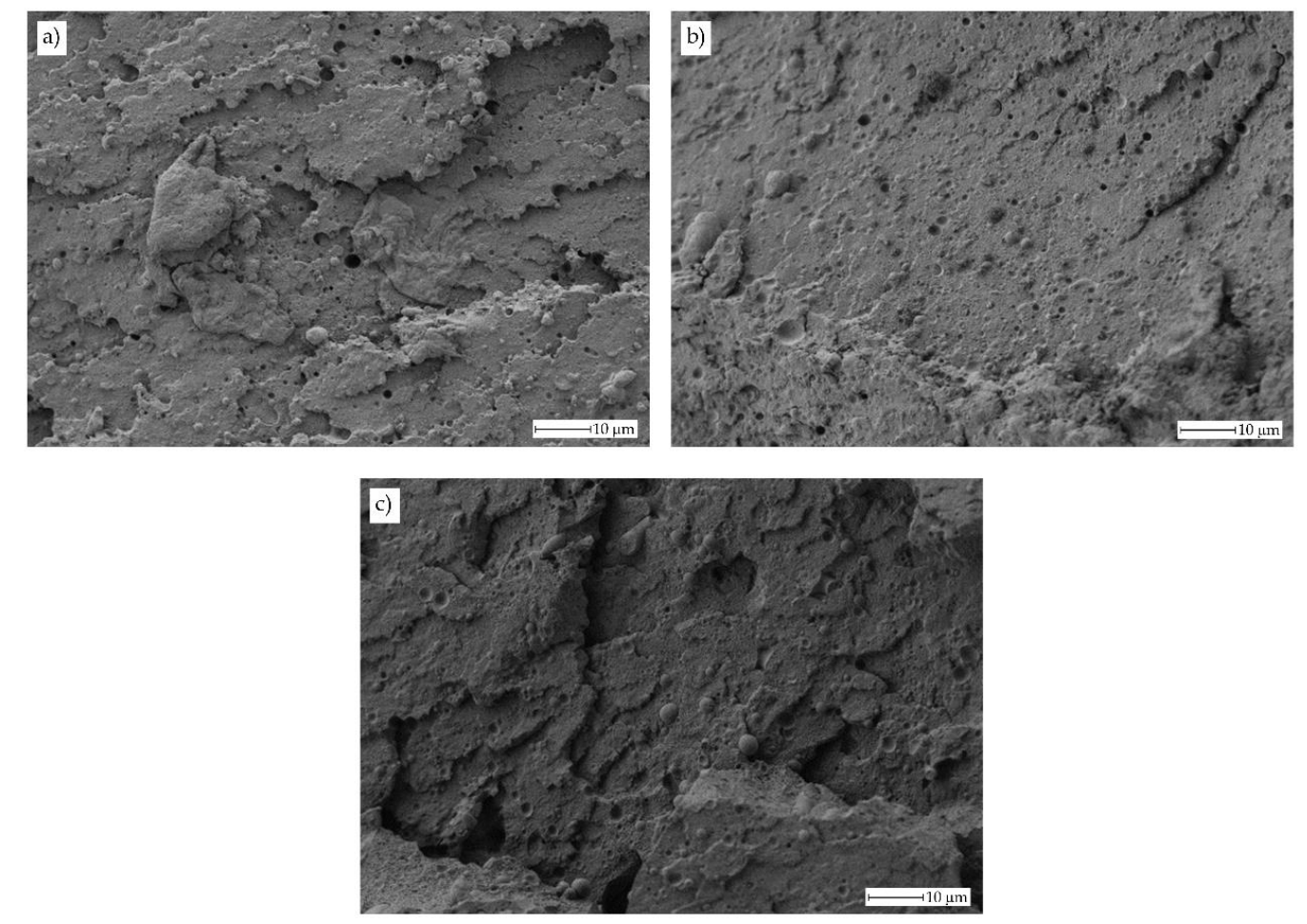

Figure 4. Field emission scanning electron microscope (FESEM) images of the fractured surface from an impact test at $1000 \mathrm{x}$ corresponding to compatibilized bioPET/bioPA blends with different loadings of Xibond 920 (in phr), (a) 1 phr, (b) 3 phr and (c) 5 phr.

As can be seen in Figure 5, the uncompatibilized blend (Figure 5a) shows a characteristic morphology, typical of poor polymer-polymer interactions. The particle droplet average diameter is $3.9 \pm 1.1 \mu \mathrm{m}$ as indicated previously. It is possible to observe this lack (or poor) interaction between both polymers. In fact, it is evident that some bioPA droplets have been removed (white rectangles) and there is a small gap between the bioPA spheres and the surrounding bioPET matrix (white arrows). Nevertheless, this gap is relatively low compared to other immiscible systems (it is in the nanoscale range), and this contributes to improved tensile properties and toughness as indicated previously. Furthermore, when observing Figure $5 \mathrm{~b}$ is that the droplet size has been reduced in a remarkable way in the same blend with 3 phr PS-GMA compatibilizer. The new droplet size for the compatibilized blend is $0.62 \pm 0.27 \mu \mathrm{m}$ which is remarkably lower than the average size of bioPA-rich domains in the uncompatibilized blend. In addition, the surface morphology of the polymer matrix is different. As can be seen in Figure 5a for the uncompatibilized blend, the bioPET matrix is quite smooth while this surface is completely different in the compatibilized blend (Figure $5 b$ ) since it is remarkably rougher as reported 
by Y. Pietrasanta et al. [56] on HDPE/PET blends compatibilized with glycidyl polymers. Regarding the gap between the embedded bioPA droplets, the morphology is also different since these embedded bioPA domains seem to be more embedded in the compatibilized blend. Similar findings have been reported for other PET-based immiscible blends such as those developed by C. Carrot et al. [59] (PET/PC) with a clear change in morphology in the presence of compatibilizers, O.M. Jazani et al. [60] (PET/PP), A.M. Torres-Huerta et al. [58] (PET/PLA) and (PET/chitosan), among others.
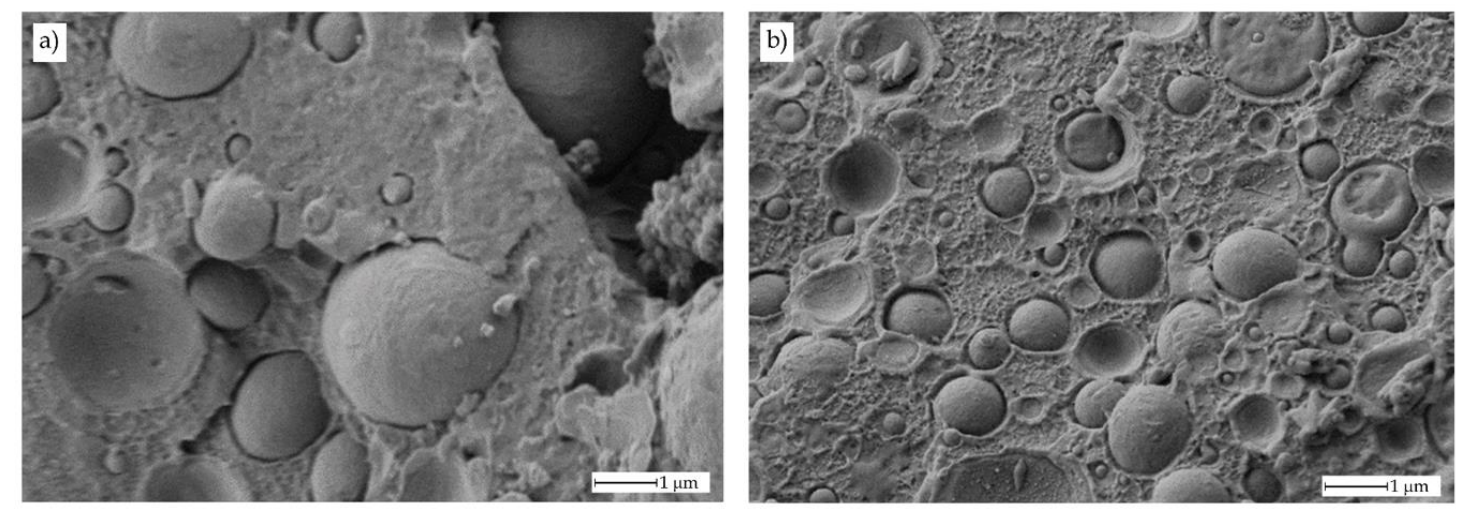

Figure 5. Detailed FESEM images corresponding to (a) uncompatibilized bioPET/bioPA blend with 30 wt \% bioPA (PET70) and (b) compatibilized bioPET/bioPA blend with 30 wt \% bioPA and $3 \mathrm{phr}$ Xibond ${ }^{\mathrm{TM}} 920$ (PET70Xibond3).

\subsection{Thermal and Thermo-Mechanical Properties of Binary BioPET/BioPA Blends}

The main thermal transitions of the developed materials are gathered in Figure 6. The neat bioPET shows in a clear way the main transitions. The step change in the $70-80^{\circ} \mathrm{C}$ range corresponds to the glass transition phenomenon $\left(T_{\mathrm{g}}\right)$ and it is 75.2 as shown in Table 4 . Then, a peak located in the $120-140{ }^{\circ} \mathrm{C}$ range corresponds to the cold crystallization process which involves crystallization of the fraction that has not been able to crystallize because of the cooling rate. This process shows a characteristic peak temperature $\left(T_{\text {Cc_PET }}\right)$ of $133.2{ }^{\circ} \mathrm{C}$. Finally, the melt process can be observed at higher temperatures of $225-260{ }^{\circ} \mathrm{C}$ with a peak temperature of $248.2^{\circ} \mathrm{C}$. The addition of bioPA up to $30 \mathrm{wt} \%$ on uncompatibilized blends does not provide any remarkable change in the $T_{\mathrm{g}}$ with values of approximately $75-76{ }^{\circ} \mathrm{C}$, very similar to neat bioPET. Although these $T_{\mathrm{g}}$ values cannot be clearly seen in Figure $6 \mathrm{a}, \mathrm{b}$, the $T_{\mathrm{g}}$ values were obtained from the zoomed DSC thermograms in the $65-85^{\circ} \mathrm{C}$ leading to the values shown in Table 4 . Regarding the cold crystallization process, bioPA plays a key role in this process. By the addition of $10 \mathrm{wt} \%$ bioPA, the peak temperature moved down to values of $121.9^{\circ} \mathrm{C}$, thus indicating bioPA enables crystallization of bioPET. Above $10 \mathrm{wt} \%$ bioPA, the cold crystallization process disappears and a slight decrease in the maximum crystallinity of bioPET (calculated with the obtained melt enthalpy values, $\Delta H_{\mathrm{m} \_ \text {PET }}$ ) can be detected as seen in Table 3 . In fact, neat bioPET shows a maximum degree of crystallinity of $22.7 \%$ and it is slightly reduced to the values of $19.9 \%$ for the uncompatibilized blend containing $30 \mathrm{wt} \%$ bioPA. The melt peak temperature does not change in a remarkable way for all the developed materials and moves between the $247-248^{\circ} \mathrm{C}$ narrow range. The effect of the PS-GMA compatibilizer is interesting. As can be seen in Table 4, a clear decrease in the crystallinity is detected from 19.9\% (uncompatibilized blend with $30 \mathrm{wt} \%$ bioPA) to $17.3 \%$ in same composition with 3 phr Xibond ${ }^{\text {TM }} 920$. These results are in total agreement with those reported by Y. Huang et al. [42] who indicated a key role of the interface on crystallization as the interface is directly related to two relevant phenomena: Crystal nucleation and crystal growth. Y. Huang et al. report the use of an epoxy resin (E-44) as a compatibilizer in PET/PA6 blends and they conclude that although the epoxy resin can positively contribute to improve mechanical properties, a decrease in crystallinity is observed with increasing E-44 content due to the formation of less perfect crystals as a consequence of the increased interactions. Moreover, this study confirmed independent 
crystallization of PET and PA6 as suggested by the wide angle of the x-ray diffraction spectroscopy (WAXD). In fact, Y. Huang et al. also report a different effect of epoxy compatibilization on hindering crystallization on both PET and PA6. The glycidyl group has more reactive points with PA6 due to the high number of hydrogen bonding in the structure while the reaction of the glycidyl group with PET is restricted to hydroxyl and carboxyl groups located at the end-chains. Y. Huang et al. reported a percentage decrease in the melt enthalpy of PET of approximately $25.9 \%$ while the decrease for PA6 is close to $40 \%$. Due to the nature of both bioPET and bioPA, the same behaviour with the glycidyl compatibilizer is expected as can be seen in Table 4 with a clear large decrease in the melt enthalpy of bioPA compared to bioPET with increasing Xibond ${ }^{\mathrm{TM}}$ 920. On the other hand, Quiles-Carrillo et al. [61] reported a clear decrease in crystallinity by reactive extrusion of PLA with maleinized hemp seed oil (MHO). This decrease was attributed to the high reactivity of the maleic anhydride groups towards the hydroxyl groups in PLA which can give chain extension, branching and even, some crosslinking, all these phenomena having a negative effect on crystallization and formation of imperfect crystals. Quiles-Carrillo et al. [62] also reported a similar effect on PLA by using another reactive compatibilizer derived from soybean oil, namely, acrylated epoxidized soybean oil (AESO).
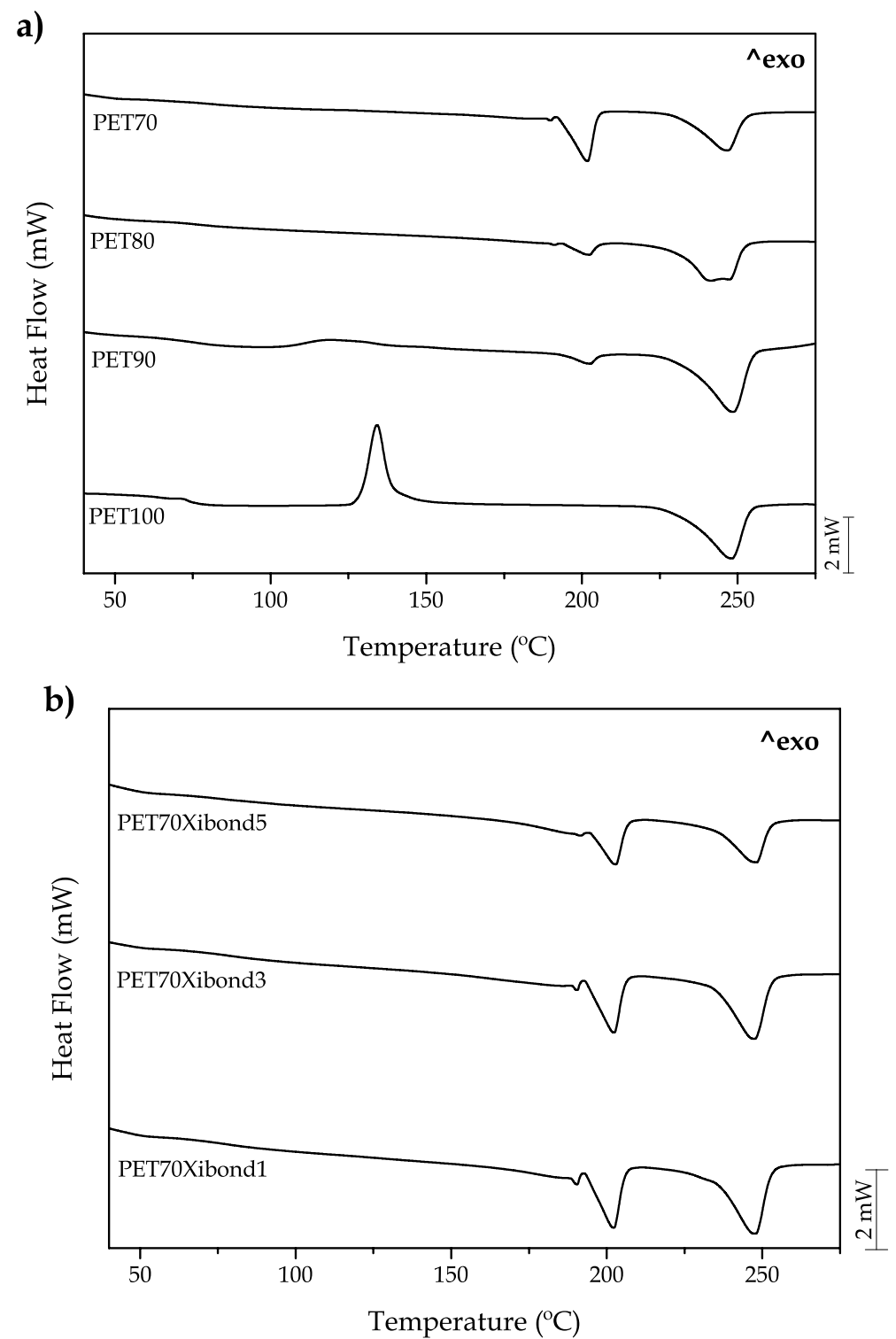

Figure 6. A plot comparative of the differential scanning calorimetry (DSC) thermograms corresponding to binary bioPET/bioPA blends. 
The immiscibility of both polymers is also evident from DSC as two melt peaks are obtained with very slight changes in their corresponding peak temperature values. BioPA shows a melt peak located at $202-203^{\circ} \mathrm{C}$ with whatever the composition may be. Nevertheless, the crystallinity is also affected by the presence of bioPET as the major component. As expected, the crystallinity of bioPA increases with increasing bioPA content from $9.8 \%(10 \mathrm{wt} \%)$ up to $16.9 \%$ (30 wt \%) since the presence of higher bioPA loadings promote more intense and independent nucleation and crystal growth processes. Nevertheless, the effect of PS-GMA is the same as in the case of bioPET. The reaction between glycidyl groups in PS-GMA with both bioPET and bioPA polymer chains leads to the formation of imperfect crystals which is responsible for a decrease in the overall crystallinity as seen in Table 4, down to values of $10.2 \%$ for the compatibilized blend with $30 \mathrm{wt} \%$ bioPA and $5 \mathrm{phr}$ Xibond ${ }^{\text {TM }} 920$. Another interesting finding is that the compatibilizer leads to a slight increase in the $T_{\mathrm{g}}$ of bioPET up to values of $78^{\circ} \mathrm{C}$ which is indicating that chain mobility is restricted. Despite this, the determination of $T_{\mathrm{g}}$ by DSC is sometimes complex and inaccurate due to the problems related to the base line and the dilution effect in polymer blends. Similar findings have been reported by D. Garcia-Garcia et al. [63], using reactive extrusion of PHB and PCL with different dicumyl peroxide (DCP) loadings. The reaction of the free radicals generated by DCP can react with both PCL and PHB thus leading to partial compatibilization. These reactions reduce chain mobility as observed by the dynamic mechanical-thermal analysis (DMTA).

Table 4. A summary of the main thermal parameters of binary bioPET/bioPA blends obtained by differential scanning calorimetry (DSC).

\begin{tabular}{|c|c|c|c|c|c|c|c|c|c|}
\hline \multirow{2}{*}{ Code } & \multicolumn{6}{|c|}{ bioPET } & \multicolumn{3}{|c|}{ bioPA } \\
\hline & $T_{\mathrm{g}}\left({ }^{\circ} \mathrm{C}\right)$ & $T_{\mathrm{cc}}\left({ }^{\circ} \mathrm{C}\right)$ & $\Delta H_{\mathrm{cc}}\left(\mathrm{J} \mathrm{g}^{-1}\right)$ & $\Delta H_{\mathrm{m}}\left(\mathrm{J} \mathrm{g}^{-1}\right)$ & $T_{\mathrm{m}}\left({ }^{\circ} \mathrm{C}\right)$ & $\chi_{c}(\%)$ & $\Delta H_{\mathrm{m}}\left(\mathrm{J} \mathrm{g}^{-1}\right)$ & $T_{\mathrm{m}}\left({ }^{\circ} \mathrm{C}\right)$ & $\chi_{c}(\%)$ \\
\hline PET100 & 75.2 & 133.2 & 27.6 & -31.8 & 248.2 & 22.7 & - & - & - \\
\hline PET80 & 75.6 & - & - & -25.3 & 247.6 & 22.6 & -4.9 & 202.4 & 10.0 \\
\hline PET70 & 75.4 & - & - & -19.5 & 246.7 & 19.9 & -12.4 & 201.9 & 16.9 \\
\hline PET70Xibond1 & 78.3 & - & - & -19.1 & 247.9 & 19.7 & -8.8 & 202.4 & 12.1 \\
\hline
\end{tabular}

Regarding thermal stability (degradation at high temperatures), Table 5 shows a summary of some thermal degradation parameters obtained by thermogravimetry (TGA). Two different characteristic temperatures are gathered in this table, the temperature required for a weight loss of $5 \%$ which is representative for the onset degradation $\left(T_{5 \%}\right)$ and the maximum degradation rate temperature $\left(T_{\max }\right)$ which corresponds to the peak maximum of the first derivative TGA curve (DTG). As can be seen, the $T_{5 \%}$ for the neat bioPET is $382.6^{\circ} \mathrm{C}$ and the addition of bioPA contributes to delay the onset degradation process as the $T_{5 \%}$ characteristic temperature is moved up to $397.4^{\circ} \mathrm{C}$ for the uncompatibilized blend containing $30 \mathrm{wt} \%$ bioPA. This is because PA1010 has more thermal stability than PET. The effect of the PS-GMA compatibilizer is a slight increase in the onset degradation temperature up to values close to $404{ }^{\circ} \mathrm{C}$ with $3 \mathrm{phr}$ Xibond ${ }^{\mathrm{TM}}$ 920. Regarding the maximum degradation rate, it is worthy to note a decreasing tendency with increasing bioPA loading on blends. This could be related to the fact that PA1010 is more thermally stable than PET but the degradation rate of PA1010 (change in weight loss with temperature) is higher than PET. For this reason, the $T_{\max }$ shows a decreasing tendency. S. Jiang et al. [64] reported that the onset degradation temperature of PA1010 is located at $419.2{ }^{\circ} \mathrm{C}$ which is remarkably higher than PET, thus contributing to improved thermal stability. 
Table 5. A summary of the thermal degradation of binary bioPET/bioPA blends obtained by thermogravimetry (TGA) analysis.

\begin{tabular}{ccc}
\hline Code & $\boldsymbol{T}_{5 \%}\left({ }^{\circ} \mathbf{C}\right)$ & $\boldsymbol{T}_{\max }\left({ }^{\circ} \mathbf{C}\right)$ \\
\hline PET100 & 382.6 & 452.6 \\
PET90 & 392.8 & 450.4 \\
PET80 & 393.2 & 443.7 \\
PET70 & 397.4 & 441.1 \\
PET70Xibond1 & 399.3 & 442.6 \\
PET70Xibond3 & 403.7 & 446.9 \\
PET70Xibond5 & 394.7 & 441.8 \\
\hline
\end{tabular}

Regarding the effect of bioPA and the PS-GMA copolymer on mechanical-dynamical thermal properties, Figure 7 gathers some characteristic curves corresponding to the neat bioPET and the uncompatibilized and compatibilized (5 phr Xibond ${ }^{\mathrm{TM}} 920$ ) blend with $30 \mathrm{wt} \%$ bioPA. Two main effects can be observed on the storage modulus, $G^{\prime}$. On the one hand, bioPET is stiffer than its blends with bioPA independently of the PS-GMA compatibilizer. T. Serhatkulu et al. [65] showed this flexibilization phenomenon on PET/PA6 blends. On the other hand, the presence of bioPA minimizes the cold crystallization process as observed in DSC. In fact, some cold crystallization occurs in bioPET/bioPA blends but DSC is not sensitive enough to detect it. However, these slight changes can be observed by DMTA as seen in Figure 7a. Another interesting phenomenon is the shift of the cold crystallization process towards lower temperatures which is in total accordance with the results obtained by DSC. The intensity of the cold crystallization can be observed in Figure $7 \mathrm{~b}$ as the shoulder located to the right side. The $T_{\mathrm{g}}$ values follow a similar tendency as that observed with DSC but DMTA seems to be more accurate to obtain these parameters. In particular, the $T_{\mathrm{g}}$ for neat bioPET is $79.9^{\circ} \mathrm{C}$ while the binary blend with $30 \mathrm{wt} \%$ bioPA shows a $T_{\mathrm{g}}$ of $81.1^{\circ} \mathrm{C}$ and the compatibilized blend (PET70Xibond5) offers a $T_{\mathrm{g}}$ of $80.5^{\circ} \mathrm{C}$.

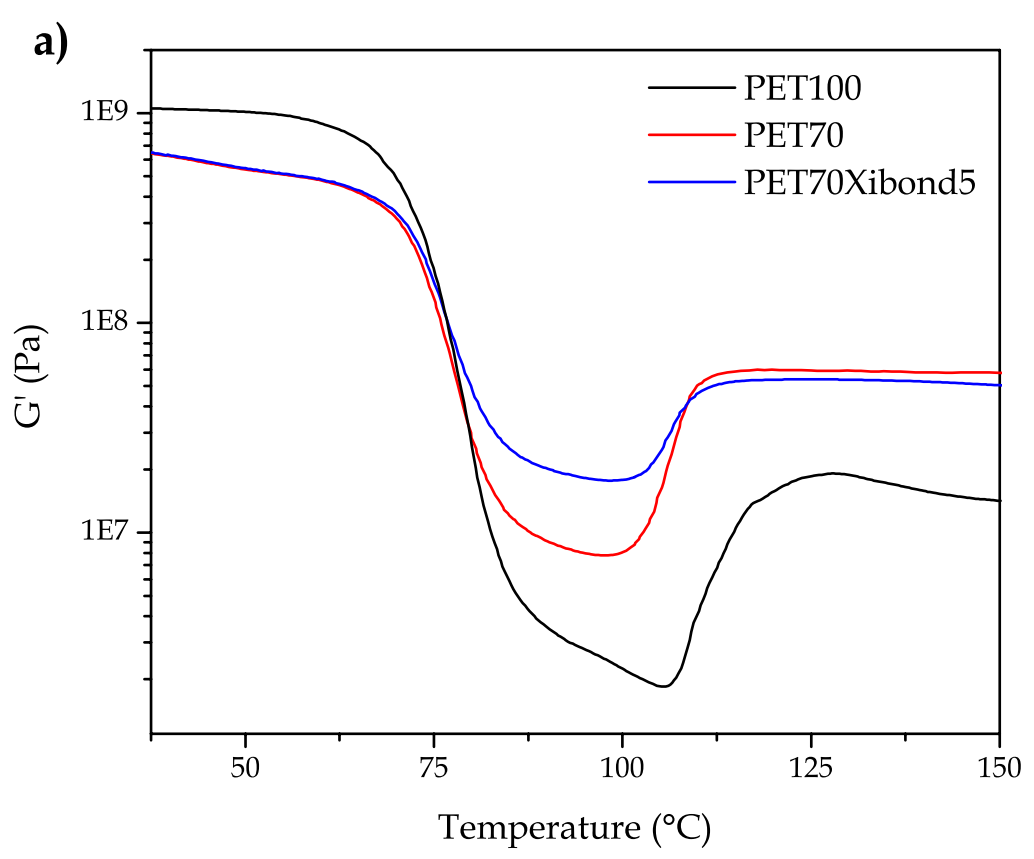

Figure 7. Cont. 


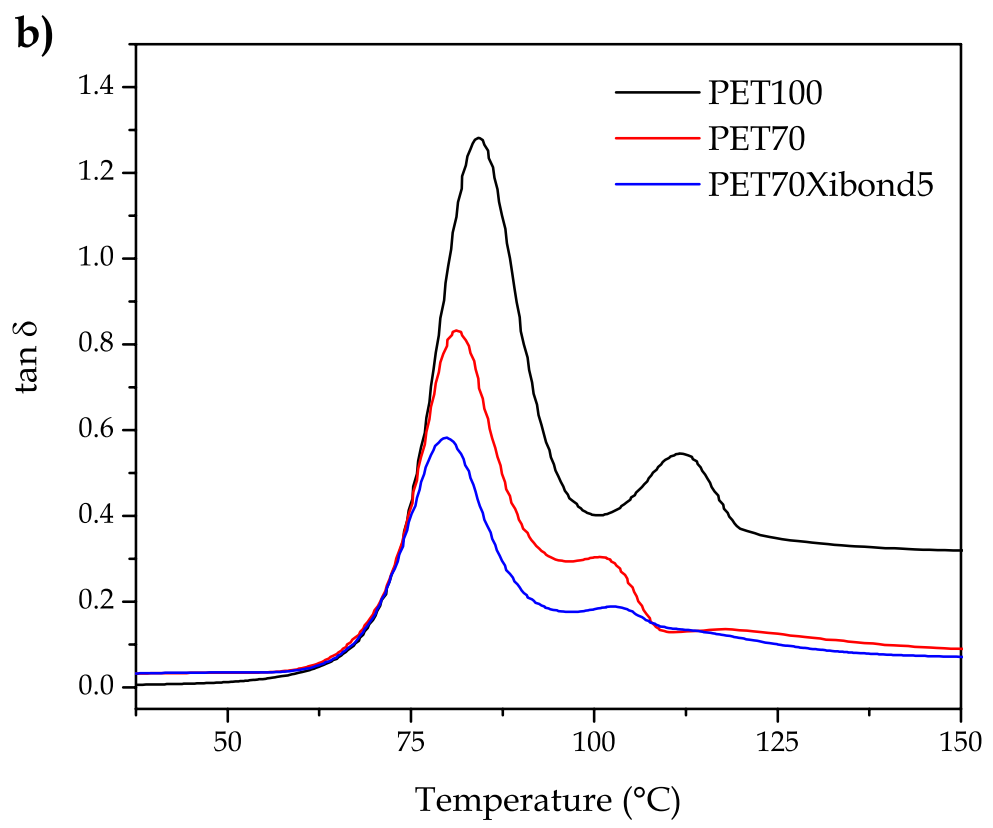

Figure 7. The dynamic mechanical thermal behaviour (DMTA) of binary bioPET/bioPA blends in terms of increasing temperature (a) storage modulus, $G^{\prime}$ and (b) dynamic damping factor, $\tan \delta$.

In addition to the dynamic mechanical-thermal analysis (DMTA), the dimensional stability has been studied by thermomechanical analysis (TMA). Figure 8 shows the TMA profiles of neat bioPET as well as the uncompatibilized and compatibilized (5 phr Xiboond ${ }^{\mathrm{TM}} 920$ ) blend containing $30 \mathrm{wt} \%$ bioPA. From these TMA curves, it is possible to see the thermal behaviour of these materials. Below $60^{\circ} \mathrm{C}$, all three materials show a linear expansion (see Table 6 for values of the coefficient of linear thermal expansion, CLTE). Below this temperature, the slope is low compared to the slope above $120^{\circ} \mathrm{C}$. The glass transition temperature $\left(T_{\mathrm{g}}\right)$ can be observed in the temperature range of $65-80^{\circ} \mathrm{C}$ as the onset of a change in the slope. The slope is very high in the rubbery state from $80^{\circ} \mathrm{C}$ up to $100{ }^{\circ} \mathrm{C}$. Then, the slope is negative which is indicating increased dimensional stability. This is caused by the cold crystallization process. As seen previously by DSC, the cold crystallization peak is clearly detectable for neat bioPET and it is almost negligible for blends with high bioPA content. These results are in accordance with those shown in Figure 6 as the highest change in the dimensions can be seen for neat bioPET due to the cold crystallization process. Nevertheless, this change is very short for the other developed materials. Finally, above $120^{\circ} \mathrm{C}$, the linear tendency stabilizes, therefore indicating the cold crystallization has finished. Regarding the CLTE values (Table 6), it is worthy to note they follow the same tendency observed for ductile properties. The CLTE for neat bioPET is $152.4 \mu \mathrm{m} \mathrm{m}^{-1} \mathrm{~K}^{-1}$, and it increases with increasing bioPA loading up to values of $347.3 \mu \mathrm{m} \mathrm{m}^{-1} \mathrm{~K}^{-1}$. The effect of the compatibilizer is that expected since the reaction between the PS-GMA and bioPET and bioPA produces a restriction on chain mobility and this has a positive effect on dimensional stability. Notably, the CLTE value for the blend with $30 \mathrm{wt} \%$ bioiPA is compatibilized with $5 \mathrm{phr}$ Xibond ${ }^{\mathrm{TM}} 920$. All these results are in total agreement with the mechanical properties above-mentioned. 


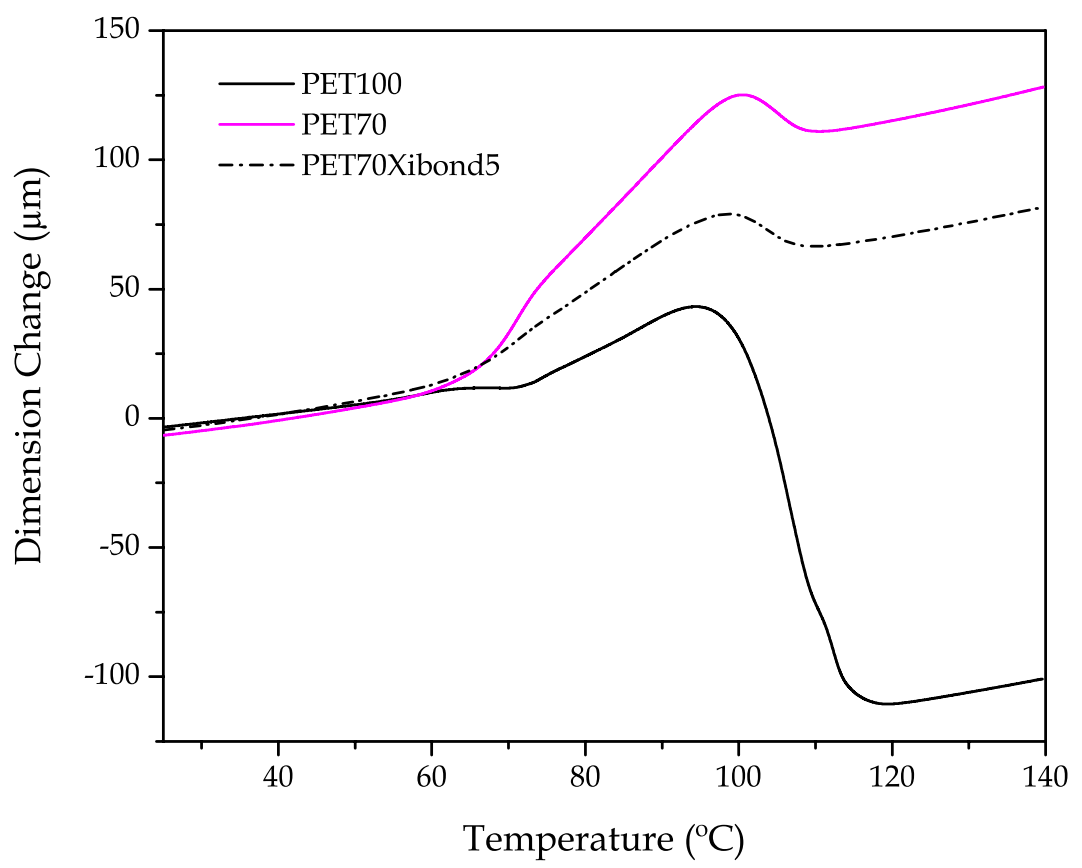

Figure 8. A comparative plot of thermomechanical behaviour of binary bioPET/bioPA blends in terms of increasing temperature.

Table 6. The calculated coefficient of linear thermal expansion (CLTE) of bioPET/bioPA blends obtained by thermomechanical analysis (TMA).

\begin{tabular}{cc}
\hline Code & CLTE $\left(\boldsymbol{\mu} \mathbf{m} \cdot \mathbf{m}^{-\mathbf{1}} \cdot \mathbf{K}^{\mathbf{- 1}}\right)^{*}$ \\
\hline PET100 & $152.4 \pm 12.2$ \\
PET90 & $162.4 \pm 10.4$ \\
PET80 & $262.1 \pm 15.1$ \\
PET70 & $347.3 \pm 22.9$ \\
PET70Xibond1 & $325.8 \pm 45.0$ \\
PET70Xibond3 & $163.2 \pm 19.3$ \\
PET70Xibond5 & $172.4 \pm 22.9$ \\
\hline
\end{tabular}

${ }^{*}$ The CLTE has been calculated form the slope below $60^{\circ} \mathrm{C}$.

\section{Conclusions}

This work reports the viability of binary blends of partially bio-based poly(ethylene terephthalate) (bioPET) and fully bio-based poly(amide) 10,10 (bioPA1010) up to $30 \mathrm{wt} \%$ bioPA1010. Due to their immiscibility, a poly(styrene-ran-glycidyl methacrylate) (PS-GMA) copolymer (Xibond ${ }^{\mathrm{TM}}$ 920) is used to provide enhanced interaction. These blends can reach up to $50 \mathrm{wt} \%$ bio-based content without compromising other mechanical and thermal properties. The effectiveness of the PS-GMA has been corroborated with an increase in toughness, elongation at yield and tensile strength for a Xibond ${ }^{\mathrm{TM}}$ 920 loading of 3 phr. A FESEM study revealed a clear droplet-like structure with a bioPET matrix embedding bioPA-rich spherical (droplets) domains. The exceptional compatibilization effect of Xibond ${ }^{\text {TM }} 920$ in this binary blend is assessed by a remarkable decrease in the droplet diameter changing from almost $4 \mathrm{~mm}$ (uncompatibilized blend with $30 \mathrm{wt} \%$ bioPA) down to values lower than $1 \mathrm{~mm}$ (compatibilized blend with $30 \mathrm{wt} \%$ bioPA and 3 phr Xibond ${ }^{\mathrm{TM}}$ 920). Regarding the thermal properties, bioPA inhibits cold crystallization and a decrease in the degree of crystallinity of bioPET due to the formation of imperfect crystals. Xibond ${ }^{\mathrm{TM}} 920$ also gives improved dimensional stability to blends thus leading to a new series of binary blends with balanced properties and a clear positive environmental impact since the bio-based content of these blends is close to $50 \mathrm{wt} \%$. 
Author Contributions: Conceptualization was devised by L.Q.-C. and R.B.; main experimental procedures were developed by M.J.; methodology, validation, and formal analysis was carried out by M.J., D.L., and S.M.-J.; investigation, resources, data curation, and writing-original draft preparation was performed by R.B. and N.M.

Funding: This research was funded by the Ministerio de Economía, Industria y Competitividad (MICINN) project number MAT2017-84909-C2-2-R. L. Quiles-Carrillo wants to thank GV for his FPI grant (ACIF/2016/182) and MECD for his FPU grant (FPU15/03812). D. Lascano wants to thank UPV for the grant received though the PAID-01-18 program. Microscopy services at UPV are acknowledged for their help in collecting and analyzing FESEM images. Authors thank Polyscope for kindly supplying Xibond ${ }^{\mathrm{TM}} 920$ to carry out this study.

Conflicts of Interest: The authors declare no conflicts of interest.

\section{References}

1. Lahtela, V.; Hyvarinen, M.; Karki, T. Composition of Plastic Fractions in Waste Streams: Toward More Efficient Recycling and Utilization. Polymers 2019, 11, 69. [CrossRef] [PubMed]

2. Avolio, R.; Spina, F.; Gentile, G.; Cocca, M.; Avella, M.; Carfagna, C.; Tealdo, G.; Errico, M.E. Recycling Polyethylene-Rich Plastic Waste from Landfill Reclamation: Toward an Enhanced Landfill-Mining Approach. Polymers 2019, 11, 208. [CrossRef] [PubMed]

3. Zheng, J.; Suh, S. Strategies to reduce the global carbon footprint of plastics. Nat. Clim. Chang. 2019, 9, 374. [CrossRef]

4. Castilla-Cortazar, I.; Vidaurre, A.; Mari, B.; Campillo-Fernandez, A.J. Morphology, Crystallinity, and Molecular Weight of Poly(epsilon-caprolactone)/Graphene Oxide Hybrids. Polymers 2019, 11, 1099. [CrossRef] [PubMed]

5. Puchalski, M.; Szparaga, G.; Biela, T.; Gutowska, A.; Sztajnowski, S.; Krucinska, I. Molecular and Supramolecular Changes in Polybutylene Succinate (PBS) and Polybutylene Succinate Adipate (PBSA) Copolymer during Degradation in Various Environmental Conditions. Polymers 2018, 10, 251. [CrossRef] [PubMed]

6. Yamane, K.; Sato, H.; Ichikawa, Y.; Sunagawa, K.; Shigaki, Y. Development of an industrial production technology for high-molecular-weight polyglycolic acid. Polym. J. 2014, 46, 769-775. [CrossRef]

7. Liminana, P.; Garcia-Sanoguera, D.; Quiles-Carrillo, L.; Balart, R.; Montanes, N. Development and characterization of environmentally friendly composites from poly(butylene succinate) (PBS) and almond shell flour with different compatibilizers. Compos. Part B Eng. 2018, 144, 153-162. [CrossRef]

8. Khalil, F.; Galland, S.; Cottaz, A.; Joly, C.; Degraeve, P. Polybutylene succinate adipate/starch blends: A morphological study for the design of controlled release films. Carbohydr. Polym. 2014, 108, 272-280. [CrossRef]

9. Garcia-Garcia, D.; Lopez-Martinez, J.; Balart, R.; Stromberg, E.; Moriana, R. Reinforcing capability of cellulose nanocrystals obtained from pine cones in a biodegradable poly(3-hydroxybutyrate)/poly(epsilon-caprolactone) (PHB/PCL) thermoplastic blend. Eur. Polym. J. 2018, 104, 10-18. [CrossRef]

10. Ferri, J.M.; Garcia-Garcia, D.; Sanchez-Nacher, L.; Fenollar, O.; Balart, R. The effect of maleinized linseed oil (MLO) on mechanical performance of poly(lactic acid)-thermoplastic starch (PLA-TPS) blends. Carbohydr. Polym. 2016, 147, 60-68. [CrossRef]

11. Domenek, S.; Feuilloley, P.; Gratraud, J.; Morel, M.H.; Guilbert, S. Biodegradability of wheat gluten based bioplastics. Chemosphere 2004, 54, 551-559. [CrossRef]

12. Song, F.; Tang, D.-L.; Wang, X.-L.; Wang, Y.-Z. Biodegradable Soy Protein Isolate-Based Materials: A Review. Biomacromolecules 2011, 12, 3369-3380. [CrossRef] [PubMed]

13. Ferrero, B.; Boronat, T.; Moriana, R.; Fenollar, O.; Balart, R. Green Composites Based on Wheat Gluten Matrix and Posidonia Oceanica Waste Fibers as Reinforcements. Polym. Compos. 2013, 34, 1663-1669. [CrossRef]

14. Xue, Y.; Lofland, S.; Hu, X. Thermal Conductivity of Protein-Based Materials: A Review. Polymers 2019, 11, 456. [CrossRef] [PubMed]

15. Masood, F.; Yasin, T.; Hameed, A. Polyhydroxyalkanoates-What are the uses? Current challenges and perspectives. Crit. Rev. Biotechnol. 2015, 35, 514-521. [CrossRef] [PubMed]

16. Wang, Y.; Yin, J.; Chen, G.-Q. Polyhydroxyalkanoates, challenges and opportunities. Curr. Opin. Biotechnol. 2014, 30, 59-65. [CrossRef] 
17. Rydz, J.; Sikorska, W.; Kyulavska, M.; Christova, D. Polyester-Based (Bio)degradable Polymers as Environmentally Friendly Materials for Sustainable Development. Int. J. Mol. Sci. 2015, 16, 564-596. [CrossRef]

18. Sharma, R.; Ray, A.R. Polyhydroxybutyrate, its copolymers and blends. J. Macromol. Sci.-Rev. Macromol. Chem. Phys. 1995, 35, 327-359. [CrossRef]

19. Liptow, C.; Tillman, A.-M. A Comparative Life Cycle Assessment Study of Polyethylene Based on Sugarcane and Crude Oil. J. Ind. Ecol. 2012, 16, 420-435. [CrossRef]

20. Boronat, T.; Fombuena, V.; Garcia-Sanoguera, D.; Sanchez-Nacher, L.; Balart, R. Development of a biocomposite based on green polyethylene biopolymer and eggshell. Mater. Des. 2015, 68, 177-185. [CrossRef]

21. Ferrero, B.; Fombuena, V.; Fenollar, O.; Boronat, T.; Balart, R. Development of natural fiber-reinforced plastics (NFRP) based on biobased polyethylene and waste fibers from Posidonia oceanica seaweed. Polym. Compos. 2015, 36, 1378-1385. [CrossRef]

22. Filgueira, D.; Holmen, S.; Melbo, J.K.; Moldes, D.; Echtermeyer, A.T.; Chinga-Carrasco, G. 3D Printable Filaments Made of Biobased Polyethylene Biocomposites. Polymers 2018, 10, 314. [CrossRef]

23. Winnacker, M.; Rieger, B. Biobased Polyamides: Recent Advances in Basic and Applied Research. Macromol. Rapid Commun. 2016, 37, 1391-1413. [CrossRef]

24. Jiang, Y.; Loos, K. Enzymatic Synthesis of Biobased Polyesters and Polyamides. Polymers 2016, 8, 243. [CrossRef]

25. Jasinska, L.; Villani, M.; Wu, J.; van Es, D.; Klop, E.; Rastogi, S.; Koning, C.E. Novel, Fully Biobased Semicrystalline Polyamides. Macromolecules 2011, 44, 3458-3466. [CrossRef]

26. Ha Thi Hoang, N.; Qi, P.; Rostagno, M.; Feteha, A.; Miller, S.A. The quest for high glass transition temperature bioplastics. J. Mater. Chem. A 2018, 6, 9298-9331.

27. Eerhart, A.J.J.E.; Faaij, A.P.C.; Patel, M.K. Replacing fossil based PET with biobased PEF; process analysis, energy and GHG balance. Energy Environ. Sci. 2012, 5, 6407-6422. [CrossRef]

28. Tachibana, Y.; Kimura, S.; Kasuya, K.-i. Synthesis and Verification of Biobased Terephthalic Acid from Furfural. Sci. Rep. 2015, 5, 8249. [CrossRef]

29. Neatu, F.; Culica, G.; Florea, M.; Parvulescu, V.I.; Cavani, F. Synthesis of Terephthalic Acid by p-Cymene Oxidation using Oxygen: Toward a More Sustainable Production of Bio-Polyethylene Terephthalate. Chemsuschem 2016, 9, 3102-3112. [CrossRef]

30. Yasuda, M.; Miyabo, A. Polyamide Derived from Castor Oil. Sen-I Gakkaishi 2010, 66, P137-P142. [CrossRef]

31. Moran, C.S.; Barthelon, A.; Pearsall, A.; Mittal, V.; Dorgan, J.R. Biorenewable blends of polyamide-4,10 and polyamide-6,10. J. Appl. Polym. Sci. 2016, 133. [CrossRef]

32. Quiles-Carrillo, L.; Montanes, N.; Boronat, T.; Balart, R.; Torres-Giner, S. Evaluation of the engineering performance of different bio-based aliphatic homopolyamide tubes prepared by profile extrusion. Polym. Test. 2017, 61, 421-429. [CrossRef]

33. Welle, F.; Bayer, F.; Franz, R. Quantification of the Sorption Behavior of Polyethylene Terephthalate Polymer versus PET/PA Polymer Blends towards Organic Compounds. Packag. Technol. Sci. 2012, 25, 341-349. [CrossRef]

34. Fabia, J.; Gawlowski, A.; Graczyk, T.; Slusarczyk, C. Changes of crystalline structure of poly(ethylene terephthalate) fibers in flame retardant finishing process. Polimery 2014, 59, 557-561. [CrossRef]

35. Kuciel, S.; Kuznia, P.; Jakubowska, P. Properties of composites based on polyamide 10.10 reinforced with carbon fibers. Polimery 2016, 61, 106-112. [CrossRef]

36. Andrzejewski, J.; Szostak, M.; Bak, T.; Trzeciak, M. The influence of processing conditions on the mechanical properties and structure of poly(ethylene terephthalate) self-reinforced composites. J. Thermoplast. Compos. Mater. 2016, 29, 1194-1209. [CrossRef]

37. Cook, W.D.; Moad, G.; Fox, B.; VanDeipen, G.; Zhang, T.; Cser, F.; McCarthy, L. Morphology-property relationships in ABS/PET blends. 2. Influence of processing conditions on structure and properties. J. Appl. Polym. Sci. 1996, 62, 1709-1714. [CrossRef]

38. Bartolotta, A.; Di Marco, G.; Farsaci, F.; Lanza, M.; Pieruccini, M. DSC and DMTA study of annealed cold-drawn PET: A three phase model interpretation. Polymer 2003, 44, 5771-5777. [CrossRef]

39. Chen, Z.; Jenkins, M.J.; Hay, J.N. Annealing of poly (ethylene terephthalate). Eur. Polym. J. 2014, 50, $235-242$. [CrossRef] 
40. Chiou, K.C.; Chang, F.C. Reactive compatibilization of polyamide-6 (PA 6)/polybutylene terephthalate (PBT) blends by a multifunctional epoxy resin. J. Polym. Sci. Part B Polym. Phys. 2000, 38, 23-33. [CrossRef]

41. Samios, C.K.; Kalfoglou, N.K. Compatibilization of poly(ethylene terephthalate)/polyamide-6 alloys: Mechanical, thermal and morphological characterization. Polymer 1999, 40, 4811-4819. [CrossRef]

42. Huang, Y.Q.; Liu, Y.X.; Zhao, C.H. Morphology and properties of PET/PA-6/E-44 blends. J. Appl. Polym. Sci. 1998, 69, 1505-1515. [CrossRef]

43. Ferreira, C.T.; da Fonseca, J.B.; Saron, C. Recycling of Wastes from Poly(ethylene tereftalate) (PET) and Polyamide (PA) by Reactive Extrusion for Preparation of Polymeric Blends. Polim.-Cienc. E Tecnol. 2011, 21, 118-122. [CrossRef]

44. Yan, Y.; Gooneie, A.; Ye, H.; Deng, L.; Qiu, Z.; Reifler, F.A.; Hufenus, R. Morphology and Crystallization of Biobased Polyamide 56 Blended with Polyethylene Terephthalate. Macromol. Mater. Eng. 2018, 303, 1800214. [CrossRef]

45. Urquijo, J.; Guerrica-Echevarria, G.; Ignacio Eguiazabal, J. Melt processed PLA/PCL blends: Effect of processing method on phase structure, morphology, and mechanical properties. J. Appl. Polym. Sci. 2015, 132. [CrossRef]

46. Ferri, J.M.; Fenollar, O.; Jorda-Vilaplana, A.; Garcia-Sanoguera, D.; Balart, R. Effect of miscibility on mechanical and thermal properties of poly(lactic acid)/polycaprolactone blends. Polym. Int. 2016, 65, 453-463. [CrossRef]

47. Xue, B.; He, H.; Zhu, Z.; Li, J.; Huang, Z.; Wang, G.; Chen, M.; Zhan, Z. A Facile Fabrication of High Toughness Poly(lactic Acid) via Reactive Extrusion with Poly(butylene Succinate) and Ethylene-Methyl Acrylate-Glycidyl Methacrylate. Polymers 2018, 10, 1401. [CrossRef]

48. Garcia-Garcia, D.; Ferri, J.M.; Boronat, T.; Lopez-Martinez, J.; Balart, R. Processing and characterization of binary poly(hydroxybutyrate) (PHB) and poly(caprolactone) (PCL) blends with improved impact properties. Polym. Bull. 2016, 73, 3333-3350. [CrossRef]

49. Hou, A.-L.; Qu, J.-P. Super-Toughened Poly(lactic Acid) with Poly(epsilon-caprolactone) and Ethylene-Methyl Acrylate-Glycidyl Methacrylate by Reactive Melt Blending. Polymers 2019, 11, 771. [CrossRef]

50. Jesus Garcia-Campo, M.; Boronat, T.; Quiles-Carrillo, L.; Balart, R.; Montanes, N. Manufacturing and Characterization of Toughened Poly(lactic acid) (PLA) Formulations by Ternary Blends with Biopolyesters. Polymers 2018, 10, 3. [CrossRef]

51. Torres-Giner, S.; Montanes, N.; Boronat, T.; Quiles-Carrillo, L.; Balart, R. Melt grafting of sepiolite nanoclay onto poly(3-hydroxybutyrate-co-4-hydroxybutyrate) by reactive extrusion with multi-functional epoxy-based styrene-acrylic oligomer. Eur. Polym. J. 2016, 84, 693-707. [CrossRef]

52. Uribe-Calderon, J.; Diaz-Arriaga, C. The effects of carbon nanotubes, blend composition and glycidyl methacrylate-grafted polypropylene compatibilizer on the morphology, mechanical and electrical properties of polypropylene-polyamide 6 blends. Polym. Bull. 2017, 74, 1573-1593. [CrossRef]

53. Shin, B.Y.; Ha, M.H.; Han, D.H. Morphological, Rheological, and Mechanical Properties of Polyamide 6/Polypropylene Blends Compatibilized by Electron-Beam Irradiation in the Presence of a Reactive Agent. Materials 2016, 9, 342. [CrossRef]

54. Li, D.; Song, S.; Li, C.; Cao, C.; Sun, S.; Zhang, H. Compatibilization effect of MMA-co-GMA copolymers on the properties of polyamide 6/Poly(vinylidene fluoride) blends. J. Polym. Res. 2015, 22, 102. [CrossRef]

55. Lima, M.S.; Matias, A.A.; Costa, J.R.C.; Fonseca, A.C.; Coelho, J.F.J.; Serra, A.C. Glycidyl methacrylate-based copolymers as new compatibilizers for polypropylene/polyethylene terephthalate blends. J. Polym. Res. 2019, 26, 127. [CrossRef]

56. Pietrasanta, Y.; Robin, J.J.; Torres, N.; Boutevin, B. Reactive compatibilization of HDPE/PET blends by glycidyl methacrylate functionalized polyolefins. Macromol. Chem. Phys. 1999, 200, 142-149. [CrossRef]

57. McLauchlin, A.R.; Ghita, O.R. Studies on the thermal and mechanical behavior of PLA-PET blends. J. Appl. Polym. Sci. 2016, 133. [CrossRef]

58. Torres-Huerta, A.M.; Palma-Ramirez, D.; Dominguez-Crespo, M.A.; Del Angel-Lopez, D.; de la Fuente, D. Comparative assessment of miscibility and degradability on PET/PLA and PET/chitosan blends. Eur. Polym. J. 2014, 61, 285-299. [CrossRef]

59. Carrot, C.; Mbarek, S.; Jaziri, M.; Chalamet, Y.; Raveyre, C.; Prochazka, F. Immiscible blends of PC and PET, current knowledge and new results: Rheological properties. Macromol. Mater. Eng. 2007, 292, 693-706. [CrossRef] 
60. Jazani, O.M.; Rastin, H.; Formela, K.; Hejna, A.; Shahbazi, M.; Farkiani, B.; Saeb, M.R. An investigation on the role of GMA grafting degree on the efficiency of PET/PP-g-GMA reactive blending: Morphology and mechanical properties. Polym. Bull. 2017, 74, 4483-4497. [CrossRef]

61. Quiles-Carrillo, L.; Montanes, N.; Sammon, C.; Balart, R.; Torres-Giner, S. Compatibilization of highly sustainable polylactide/almond shell flour composites by reactive extrusion with maleinized linseed oil. Ind. Crops Prod. 2018, 111, 878-888. [CrossRef]

62. Quiles-Carrillo, L.; Duart, S.; Montanes, N.; Torres-Giner, S.; Balart, R. Enhancement of the mechanical and thermal properties of injection-molded polylactide parts by the addition of acrylated epoxidized soybean oil. Mater. Des. 2018, 140, 54-63. [CrossRef]

63. Garcia-Garcia, D.; Rayon, E.; Carbonell-Verdu, A.; Lopez-Martinez, J.; Balart, R. Improvement of the compatibility between poly(3-hydroxybutyrate) and poly(8-caprolactone) by reactive extrusion with dicumyl peroxide. Eur. Polym. J. 2017, 86, 41-57. [CrossRef]

64. Jiang, S.; Mi, R.; Yun, R.; Qi, S.; Zhang, X.; Lu, Y.; Matejka, V.; Peikertova, P.; Tokarsky, J. Structure and properties of kaolinite intercalated with potassium acetate and their nanocomposites with polyamide 1010. J. Thermoplast. Compos. Mater. 2017, 30, 971-985. [CrossRef]

65. Serhatkulu, T.; Erman, B.; Bahar, I.; Fakirov, S.; Evstatiev, M.; Sapundjieva, D. Dynamic-mechanical study of amorphous phases in poly(ethylene terephthalate)/nylon-6 blends. Polymer 1995, 36, 2371-2377. [CrossRef]

(C) 2019 by the authors. Licensee MDPI, Basel, Switzerland. This article is an open access article distributed under the terms and conditions of the Creative Commons Attribution (CC BY) license (http://creativecommons.org/licenses/by/4.0/). 